\title{
INTERFACES ENTRE PRÁTICAS INDIGENISTAS DE ESTADO E POLITICAS PÚBLICAS NO ENFRENTAMENTO DA COVID-19 NO VALE DO JAVARI: O CASO DO POVO TÜKÜNA-KANAMARI
}

\author{
Danielle Moreira Brasileiro 11 \\ Ricardo Sallum Freire12
}

\begin{abstract}
RESUMO
Neste artigo seus autores procuram registrar e analisar o papel das políticas públicas voltadas à proteção de povos indígenas no Brasil durante a crise sanitária imposta pela Pandemia do Novo Coronavírus (Sars-CoV-2). Tem-se como base destas análises uma série de eventos e episódios vivenciados nas práticas indigenistas destes autores junto a uma das unidades descentralizadas da Fundação Nacional do Índio (Funai), a Coordenação Regional do Vale do Javari (CR-VJ). Estes, por sua vez, são analisados frente às reflexões estabelecidas na tese de doutorado de Brasileiro (2020), em específico naquilo que se refere à materialização das políticas públicas nas vidas dos Kanamari do Vale do Javari. Privilegiouse ainda a metodologia da pesquisa bibliográfica e documental, com os dados primários coletados e a reflexão das ações como agentes públicos, com o objetivo de redigir este artigo. E os dados secundários foram coletados de trabalhos publicados e devidamente atualizados.
\end{abstract}

Palavras-Chaves: Pandemia Covid 19; Terra Indígena Vale do Javari; Tüküná-Kanamari; política pública.

\section{INTERFACES BETWEEN INDIGENOUS STATE PRACTICES AND PUBLIC POLICIES IN COPING WITH COVID-19 IN THE JAVARI VALLEY: THE CASE OF THE TÜKÜNA-} KANAMARI PEOPLE

\begin{abstract}
In this article, its authors seek to register and analyze the role of public policies aimed at protecting indigenous peoples in Brazil during the health crisis imposed by the New Coronavirus Pandemic (SarsCoV-2). Based on these analyzes is a series of events and episodes experienced in the indigenous practices of these authors at one of the decentralized units of the Fundação Nacional do Índio (Funai), the Regional Coordination of Vale do Javari (CR-VJ). These, in turn, are analyzed in view of the reflections established in the doctoral thesis of Brasileiro (2020), specifically in what refers to the materialization of public policies in the lives of the Kanamari from Vale do Javari. The methodology of bibliographic and documentary research was also privileged, with the primary data collected and the reflection of actions as public agents, with the objective of writing this article. Secondary data was collected from published works and duly updated.
\end{abstract}

Key words: Pandemia Covid 19; Vale do Javari Indigenous Territory; Tüküná-Kanamari; public policy.

\footnotetext{
11 Doutora em Sociedade e Cultura na Amazônia pela Universidade Federal da Amazônia, sob a orientação da professora doutora Heloisa Helena Corrêa da Silva, e indigenista servidora da Coordenação Regional Vale do Javari da Funai. Membro do Grupo de Pesquisa Questão Social e Serviço Social, liderado pela professora doutora Heloisa Helena Corrêa da Silva.

12 Mestre em Geografia pelo Instituto de Geociências da Universidade Federal da Bahia (IGEO-UFBA) e indigenista servidor da Coordenação Regional Vale do Javari da Funai.
} 


\section{INTERFACES ENTRE PRÁCTICAS ESTATALES INDÍGENAS Y POLÍTICAS PÚBLICAS PARA ENFRENTAR EL COVID-19 EN EL VALLE DE JAVARI: EL CASO DEL PUEBLO TÜKÜNA-KANAMARI}

\section{Resumen}

En este artículo, los autores buscan registrar y analizar el papel de las políticas públicas dirigidas a proteger a los pueblos indígenas en Brasil durante la crisis de salud impuesta por la Nueva Pandemia de Coronavirus (Sars-CoV-2). A partir de estos análisis se desprende una serie de hechos y episodios vividos en las prácticas indígenas de estos autores, junto con una de las unidades descentralizadas de la Fundación Nacional del Indio (Funai), la Coordinación Regional de Vale do Javari (CR-VJ) que se analizan junto con la información y reflexiones establecidas en la tesis doctoral de Brasileiro (2020), específicamente en lo que respecta a la materialización de políticas públicas en la vida de los Kanamari de Vale do Javari. También se privilegió la metodología de la investigación bibliográfica y documental, con los datos primarios recogidos y la reflexión de las acciones como agentes públicos, con el objetivo de redactar este artículo. Los datos secundarios fueron recolectados de trabajos publicados y debidamente actualizados.

Palabras clave: Covid Pandemia 19; Tierra Indígena Vale do Javari; Tüküná-Kanamari; políticas públicas.

\section{INTRODUÇÃO}

Neste artigo os autores procuram registrar e analisar o papel das políticas públicas voltadas à proteção de povos indígenas no Brasil durante a crise sanitária imposta pela Pandemia do Novo Coronavírus (Sars-CoV-2) com destaque na Amazônia. Tem-se como base destas análises uma série de eventos e episódios vivenciados nas práticas indigenistas destas/es autoras/es junto a uma das unidades descentralizadas da Fundação Nacional do Índio (FUNAI), a Coordenação Regional do Vale do Javari (CR-VJ) que são aqui cotejadas om as informações e reflexões estabelecidas na tese de doutorado de Brasileiro (2020), em específico naquilo que se refere às materializações de políticas públicas que incidem nas vidas dos Kanamari do Vale do Javari. Além disso, enquanto metodologia de pesquisa adotada para a produção deste artigo foram consultados, como suporte das análises feitas, documentos oficiais publicados antes e durante a Pandemia pelas instituições públicas responsáveis por gerir a crise sanitária atual no Brasil e, mais especificamente, na Terra Indígena Vale do Javari (TIVJ); cartas, notas e ofícios produzidos pelas organizações indígenas de base do Vale do Javari; além de reportagens e notícias que circularam através dos diversos canais midiáticos atualmente existentes.

A Pandemia da COVID-19, que causou uma das maiores crises sanitárias mundiais da história, foi registrada oficialmente na Terra Indígena (TI) Vale do Javari no início do mês de junho, sendo membros do povo Tüküná-Kanamari os primeiros indígenas a terem contato com a doença no âmbito deste território. Os primeiros casos da COVID-19 no Vale do Javari foram confirmados por equipe do Polo Indígena de Saúde Médio Javari do Distrito Sanitário Especial 
do Vale do Javari (DSEI-VJ/Sesai) na aldeia Tüküná-Kanamari São Luís. Em poucos dias novos casos foram identificados por este Distrito em outras duas aldeias deste povo no médio curso do Rio Javari, as aldeias Lago do Tambaqui e Irari. As vias do contágio destas comunidades ainda são incertas e as suspeitas que pairam sobre estas envolvem acusações recíprocas entre indígenas e agentes públicos de saúde. Por um lado, os indígenas do Médio Javari afirmam que foram os profissionais da saúde que, infectados, levaram o vírus à comunidade (Oficio n ${ }^{\circ}$. 10/AKAVAJA/ATN/2020 Atalaia do Norte - AM, 05 de Junho de 2020). Por outro, o DSEI-VJ lançou Nota (Nota à Imprensa exarada pela Secretaria Especial de Saúde Indígena - SESAI/MS, em 04 de junho de 2020, referente a "Quatro profissionais do Distrito Especial Indígena Vale do Javari testam positivo para COVID-19”), onde afirma que estes indígenas, apesar de todas as recomendações da equipe de saúde para que permanecessem em isolamento, continuavam insistentemente travando contato com regionais que transitam pelos limites 13 da TI Vale do Javari para a troca e comércio de produtos.

Procurou-se ao longo deste artigo analisar uma série de fatos vivenciados pelos autores em suas práticas indigenistas enquanto agentes públicos. Para tanto, o presente trabalho se organiza em 5 seções. Na primeira delas, busca-se situar o leitor quanto à "Localização do Universo Geográfico e População”, caracterizando em linhas gerais a Terra Indígena Vale do Javari, situada no munícipio de Atalaia do Norte-AM, e o povo Tüküná-Kanamari que nela habita. Na segunda seção, sobre "a busca por melhores condições para a efetivação das políticas públicas no contexto amazônico", problematiza-se, com base em referenciais teóricas, questões acerca das inadequações históricas de ações institucionais no contexto amazônico.

\section{LOCALIZAÇÃO DO UNIVERSO GEOGRÁFICO E POPULAÇÃO}

A T.I Vale do Javari está localizada na região do rio (Javari) que leva nome, sendo este o principal marco geográfico da fronteira entre o Brasil e o Peru. Segunda maior terra indígena em área contínua do Brasil, possui mais de oito milhões de hectares (compreende 8.544.448 hectares) de terras demarcadas.

Transcorridos dezenove anos de sua homologação (ocorrida em 2001), a densidade demográfica na TI Vale do Javari, saltou de 3.100 para aproximadamente seis mil e duzentos

\footnotetext{
13 O Médio Rio Javari, às margens dos quais se situam as aldeias Tüküná-Kanamari São Luís, Lago do Tambaqui e Irari, além de uma aldeia Matsés-Mayoruna, Lago Grande, representa parte dos limites setentrionais da TI Vale do Javari ao mesmo tempo em que define a fronteira entre Brasil e Peru. Sendo assim, regionais brasileiros e peruanos circulam livremente por esta que é a principal via de acesso entre os povoados e cidades próximas.
} 
indígenas (6.200) aldeados. Oriundos das etnias Marubo, Kulina (Pano), Mayoruna, Matis, Kanamari, Korubo e Tsohom Dyapá. Não há demarcação territorial por povo, e em relação a outras TI's no Brasil, possui outra especificidade, além dos indígenas vivendo comunidades aldeadas (63), tem-se ainda o compartilhamento do território com as dezesseis referências (16) de grupos isolados e dois grupos recém-contatos. Esta complexidade por si só envolve toda uma atenção e cuidado diferenciados com qualquer ação e ou política a ser pensada para este território. No Vale do Javari, conhecidos em geral como Kanamari, os falantes da língua Katukina, têm reivindicado sua autodenominação através do etnômio Tüküná que, em sua língua, pode significar "homem verdadeiro", ou ainda o mesmo que "gente". O próprio termo é assim usado para sua autodenominação, que em sua pronuncia deriva o vocábulo Tâkâna (FUNAI, 2008; NEVES, 1996). Numa conceituação deste vocábulo, Costa (2007, p.24) diz que “Tüküná, é claro, é um tipo de termo altamente difundido nas terras baixas da América do Sul. Todos os índios parecem possuir um termo que usam mais ou menos como uma autodesignação e que significa "pessoa"'.

Além dos trabalhos mais recentes dos etnógrafos que se debruçaram sobre as problemáticas em torno do Povo Tüküná-Kanamari, outras importantes fontes para o estudo destes indígenas são os registros e anotações de Tastevin, sacerdote missionário que esteve com os Kanamari em 1910, quando estes habitavam no domínio apostólico dos padres, no Médio Juruá.

Os Kanamari, segundo dados do IBGE (2010), se constituem atualmente em um povo de 4.007 indígenas, sendo um total de 2.145 homens e 1.862 mulheres. No Vale do Javari, sua população se contabiliza em um total de 1.438 pessoas, atualmente distribuídas em 9 aldeias ao longo do rio Itacoaí (Massapê, Cajueiro, Kawiyá, Bananeira, Remansinho, Terra Nova, Hobanã, Trakoa e Kumaru), cinco aldeias no médio curso do rio Javari (Irari, Lago do Tambaqui, Santo Eusébio, São Luís e Lago do Caxias) e uma aldeia no rio Jutaí (Jarinal). Anjos (2011), em estudo sobre a língua Katukina, diz que os Kanamari e os Katukina do Biá coabitavam a mesma região, se considerando um mesmo povo e, a partir de divisões e conflitos internos, houve a separação étnica e sua consequente dispersão territorial. Carvalho (2002, p.100), afirma que desentendimentos, muito provavelmente incrementados com incorporações de membros de outros grupos, seriam constantes e que entre os Katukina "[...] há uma extensa cronologia de desavenças, rivalidades e mortes entre Dyapá, seguidas, invariavelmente, de cisões e reordenamentos espaciais". 
Traço forte dos Katukina em geral, tem-se que as aldeias Kanamari são muito dinâmicas. Mudam frequentemente de localização e de composição (FUNAI 2008 p.46). Segundo Neves (1996, p.18), a visitação entre grupos locais, seja por ocasiões especiais, seja através da simples visita entre familiares, são espaços excepcionais para a afirmação de laços sociais e para a constituição de novas alianças, quando da mobilidade geográfica, combinando as condições ambientais vigentes e a produção dos meios de sobrevivência, a nomeação do grupo (Dyapá). Um ponto mais facilmente notado é o fato de as aldeias serem formadas por parentelas bilaterais, reunidas em torno de uma autoridade congregadora. (FUNAI, 2008, p.47).

Estudos mais recentes ratificam sua mobilidade como um traço cultural Kanamari e confirmam a sua procedência na bacia do Juruá (REESINK, 1994, 1993; NEVES, 1996; CARVALHO, 2002; LABIAK, 2007; e COSTA, 2007). Em uma perspectiva geográfica da dispersão de grupos que falam a mesma língua Kanamari e teriam uma mesma cosmovisão a partir do processo de criação do mundo, "daqueles que foram criados a partir do coco jaci", Labiak (2007, p. 51) diz que "[...] encontram-se atualmente nas regiões dos rios: altos Jutaí e Itacoaí. Médios Javari, Japurá e Juruá; baixo Itucumã, afluente do Tarauacá. Alto e médio Xeruã, todos basicamente no sudoeste do Estado". Desse universo de localização, hoje estão situados em diferentes Terras Indígenas (TIs): na TI Vale do Javari, onde ocupam os rios Javari, Itacoaí e Jutaí; na TI Mawetek próxima ao sul da TI Vale do Javari e que compreende os tributários da margem esquerda do médio Juruá; a TI Kanamari do Médio Juruá, situada nos tributários da margem direita do Juruá, rio abaixo da cidade de Eirunepé; e duas pequenas áreas no Japurá, no município de Carauari, e no rio Xeruã, município de Itamarati-AM, onde existem duas aldeias Kanamari na TI Kanamari próximos a TI Deni, conforme quadro a seguir:

A chegada dos Kanamari ao Vale do Javari, segundo Costa (2007, p. 45) foi gradual. O rio Itacoaí, não era desconhecido dos Kanamari, ao contrário, sabia-se de sua fartura de caça e tracajás (sobretudo na busca de seus ovos), e desta maneira já se constituía em rota e espaço frequentado nos meses de verão. O conjunto de informações que a análise dos dados secundários oferecem possibilita afirmar-se que as populações residentes na TI Vale do Javari historicamente foram excluídas das políticas públicas, no caso específico das condições sanitárias apropriadas, implicando em baixo impacto cultural e falta de garantia de atenção à saúde destes povos.

\section{A BUSCA POR MELHORES CONDIÇÕES PARA A EFETIVAÇÃO DAS POLÍTICAS PÚBLICAS NO CONTEXTO AMAZÔNICO}


O meio e o homem, numa relação dialógica imprime um ao outro a sua marca. Compreende-se, assim como assevera Neves (2006, p. 53), que parte dos problemas sensíveis no que se refere à condução e à discussão sobre Amazônia, por parte de cidadãos organizados, agentes governamentais, como também cientistas, políticos e intelectuais, de estratégias voltadas para a "ocupação" e o desenvolvimento sustentável da Amazônia estão diretamente ligados ao completo desconhecimento, ou até mesmo desinteresse, com relação à história milenar de ocupação humana da região. Pondera-se que esta preocupação seja um legado também deixado pela obra de Leandro Tocantins, que assevera que a preocupação com a adequação das ações institucionais, sobretudo governamentais para o indivíduo amazônico deva ser trazida através de problematizações e responsabilizações para com suas ações em prol de um bem viver da população regional e não daqueles que da Amazônia só tiraram o proveito. Assim, problematiza o autor:

A vida amazônica nos maiores centros de cultura, e nas cidades menores do vale, alcançou aquele equilíbrio que deve caracterizar a interdependência plástica entre homem e região? Que se fez, em matéria de pesquisas, de estudos, de experimentação, dentro de critérios sociológico, ecológico, antropológico-social, destinados a orientar governos, empresas privadas, empreendimentos humanos, na edificação de nosso sistema de vida? (TOCANTINS, 1973, p. 287).

Em sua destacada obra, "O rio comanda a vida", Tocantins (1973) já aponta o que seria um erro crasso brasileiro. A uniformidade com que se procurou e ainda se procura resolver problemas num Brasil diverso e vário teria sido, segundo o autor, também, um dos muitos fatos responsáveis pelo subdesenvolvimento em que se encontram certas regiões brasileiras (idem, p. 288). Em sua reflexão Tocantins ratifica ainda que é "bem conhecida à tendência uniforme com que se aplicam neste país, leis e regulamentos”. Não obstante, ressalta o autor, “essa perigosa tendência uniforme no exame de situações e na solução de problemas brasileiros, se afasta, pouco a pouco, com a presença na vida pública de novas gerações libertas do academicismo e do bacharelismo estéreis, sem se descuidar ainda dos perigos da ortodoxia econômica" (Idem, ibidem). Para fins deste estudo, adota-se os ensinamentos e postulados deste amazônida, que na sua interpretação da Amazônia ratifica que as esferas social e econômica se conjuguem habilmente para o progresso da sociedade e o bem-estar humano (idem, p. 286). Defende-se que estudos e pesquisas foquem este bem viver e que corroborem, sobretudo com as políticas 
públicas para e da Amazônia, "do natural ao social não deve existir nenhum artifício ou embaraço que perturbe o equilíbrio, a harmonização, o entrelaçamento" (id. p. 290).

Para Marcilio de Freitas, (2017, p. 2), "passado e presente, na Amazônia, a natureza continua desafiando a cultura", as intervenções do conhecimento científico e tecnológico na “construção de modelos de desenvolvimento sustentável para esta região são dimensões que precisam ser melhores exercitadas pelos gestores e os seus povos tradicionais". É preciso o reconhecimento ancestral milenar da relação sinergética entre os povos tradicionais na Amazônia e o seu meio na formação atual de seu ecossistema. É preciso ainda apreender no âmbito das políticas públicas o comando dos rios e da vida na Amazônia, sob pena de contribuirmos para a extinção dos povos e suas culturas na Amazônia.

No âmbito da aplicação das políticas públicas faz-se necessário a consideração dos processos histórico-estruturais de cada região e de cada povo em que incidirá tais políticas. Heloisa Helena Corrêa da Silva, em estudo sobre a política da Assistência Social no Vale do Juruá, refere-se a essa premissa e traz outras contribuições às pesquisas no campo da análise de políticas públicas, dentre as quais a acuidade da análise sociohistórica, o olhar atento para a formação social e econômica, que envolvem a questão indígena, os ciclos de exploração do extrativismo e as formas de dependências em que se colocou a Amazônia em relação aos outros Estados brasileiros e aos países centrais e os seus planos de assistência (CORRÊA DA SILVA, 2012, p. 173).

No Vale do Javari, assim como no Vale do Juruá, a questão social revelada, aponta para os aspectos econômicos, sociais e culturais de empobrecimento das populações que o habitam. Como afirma Corrêa da Silva (2012, p. 188), essa situação: “(...) é fruto dos ciclos de desenvolvimento associado ao descaso das políticas governamentais que nunca responderam às demandas dos problemas sociais mais visíveis como a exploração do seringueiro, a questão indígena, o preconceito étnico". Para a autora, desigualdade e pobreza em lugares recônditos amazônicos são fenômenos presentes desde tempos de outrora até os dias atuais e, embora ética e socialmente similares, essas condições são econômica e politicamente diversas.

As políticas públicas precisam refutar quaisquer resquícios passados de um pensamento que imaginou a Amazônia como sendo um espaço vazio, sem gente e sem história. É preciso se ter em conta nas ações governamentais para a região a influência dos regimes hídricos nas sociedades amazônicas atuais para uma efetividade cidadã dessas ações. Como assevera Leandro Tocantins em seu legado, os fracassos das políticas públicas nacionais endereçadas ao 
mundo amazônico foram sucessivos e quase sempre irreversíveis por desprezarem, sobretudo, o fator ativo da hidrografia nas organizações sociais que se re-produzem na região.

\section{AS INADEQUAÇÕes das POLÍTICAS PÚbliCAS ENTRE OS TÜKÜNA- KANAMARI PRÉ-PANDEMIA}

O caso específico dos embates em torno da efetivação de políticas públicas em atendimento ao povo Tüküná-Kanamari do Vale do Javari expressa algumas dimensões dos dilemas criados pela inadequação dessas políticas para a realidade socioespacial e sociocultural destes indígenas. Dentre outras, cabe aqui destacar aquelas voltadas à melhoria das condições sanitárias de vida deste povo. Isto tem sido um dos principais focos da luta social travada por estes indígenas, principalmente, buscando reduzir a mortalidade e a desnutrição infantil, que têm índices alarmantes entre sua população, o alcoolismo e o suicídio que afeta principalmente jovens e adolescentes Tüküná-Kanamari.

Apesar dos esforços das equipes da CR-VJ/Funai e do DSEI-VJ/Sesai e deste ter afirmado que os Tüküná-Kanamari representarem uma prioridade na atuação neste Distrito de Saúde Indígena, assuntos estes tratado na tese de Brasileiro (2020), detaca-se que uma revisão da atuação estatal junto a estes indígenas é imperativa, pois em que pese os consideráveis gastos envolvidos nesse atendimento, não se pôde constatar sua real eficácia. O que imputa dizer que as instituições indigenistas, sobretudo a Sesai e a Funai precisam ainda aprender como trabalhar com os Tüküná-Kanamari.

Estes fatores potencializam os riscos atuais a que estão expostos os Tüküná-Kanamari do Vale do Javari diante da Pandemia do Novo Coronavírus, além da reconhecida vulnerabilidade de indígenas em geral vinculada ao patrimônio genético destes povos e suas imunidades para as morbidades respiratórias e virais. Ou seja, à sua vulnerabilidade gerada por fatores biológicos e genéticos, soma-se a de caráter histórico e social, constituindo um cenário muito preocupante e frágil para estes indígenas e para os agentes de Estado responsáveis em dar respostas emergenciais para combate ao novo Coronavírus.

No âmbito regional do órgão indigenista oficial brasileiro, a CRVJ/FUNAI no Vale do Javari, apresenta-se com um baixíssimo quadro funcional14, a ausência de um Coordenador

14 Importante destacar que neste contexto foi solicitada à Presidência da FUNAI uma atenção para uma força tarefa quanto ao número de Servidores no Vale do Javari e foi disponibilizado um número de cinco Servidores para o auxílio neste contexto da pandemia. 
Técnico Local (CTL) junto aos Kanamari 15, especificamente do rio Itacoaí, a falta de formação e qualificação técnica da e na equipe CRVJ sobre as orientações das questões de saúde e sanitárias recomendadas pela OMS para as populações tradicionais indígenas e profissionais como um todo (em todas as instituições que lidam com os Kanamari) referente às temáticas necessárias para a discussão nas questões pertinentes a pandemia pelo Covid 19. Vê-se extremamente necessárias e urgentes ações mais permanentes e edificantes de melhores condições de trabalho e de respostas aos povos indígenas.

\section{ENFRENTANDO A CRISE: ENTRE RESPOSTAS GENERALIZANTES DO ESTADO E ARRANJOS LOCAIS PARA O ENFRENTAMENTO DA COVID-19 NO VALE DO JAVARI.}

\subsection{Resolução conjunta de instituições públicas e organizações indígenas para garantia de isolamento social das comunidades}

Diante da série de notícias que reportavam o avanço da Pandemia do Novo Coronavírus em território brasileiro e antes mesmo de se terem registrado casos da doença na Região Norte do País, a CRVJ/FUNAI organizou uma reunião interinstitucional em 17 de março de 2020 diante a qual foi pactuada a "Resolução Conjunta Funai- Sesai-Condisi-Univaja". Entre outras ações, o documento assinado por essas instituições (CR-VJ/Funai, DSEI-VJ/Sesai, Conselho Distrital de Saúde Indígena do Vale do Javari - CONDISI-VJ e da União dos Povos Indígenas do Vale do Javari - UNIVAJA) previu a adoção de medidas emergenciais para a garantia do retorno imediato dos indígenas do Vale do Javari que se encontravam na Sede Municipal de Atalaia do Norte/AM para suas respectivas aldeias, o que incluiu a distribuição de grande volume de combustível para as embarcações destes indígenas.

Apesar de todos os esforços despendidos e dos gastos de recursos públicos para a garantia do deslocamento precoce das famílias indígenas em direção a suas comunidades antes da Pandemia ter alcançado a Amazônia Ocidental e a região do Alto Solimões, muitos indígenas acabaram permanecendo na cidade de Atalaia do Norte. Um dos principais motivos que retardaram o retorno destes indígenas, na sua maioria estudantes e seus familiares, foram às dúvidas quanto à continuidade das atividades escolares ${ }^{16}$.

\footnotetext{
15 Há um Servidor que acumula duas jurisdição de CTL para que minimamente os Tüküná do rio Itacoaí não fiquem sem atendimento

${ }^{16}$ É necessário se destacar que, apesar de já contarem com escolas indígenas na maior parte das aldeias do Vale do Javari, são poucas as escolas que atendem aos estudantes de nível médio de ensino. Além disso, duvidando da 
Com isso, apesar das contundentes orientações da CR-VJ/Funai e do "Comitê Municipal de Enfrentamento à COVID-19" para que se encerrasse o ingresso de pessoas na Terra Indígena, diversas e esporádicas demandas de retorno de indígenas para suas aldeias surgiam, na medida em que os informes oficiais noticiavam a aproximação da Pandemia da região. Assim, estratégias e protocolos de segurança para tais retornos tiveram que ser exaustivamente discutidos e providenciados, através de pactuações entre o Movimento Indígena, o DSEI$\mathrm{VJ} /$ Sesai e a CR-VJ/Funai em uma série de reuniões, muitas delas bastante tensas, onde se contrapunham os interesses particulares das famílias em "fugir" da Pandemia e os interesses coletivos das comunidades que já se encontravam em isolamento social no interior da Terra Indígena. Decorrido cerca de um mês após o início do retorno dos indígenas para as aldeias e de alguns movimentos erráticos de alguns grupos, contando inclusive com o aval de membros do movimento indígena e até mesmo de certas autoridades públicas, findaram-se os deslocamentos de indígenas em direção ao interior da TI Vale do Javari.

\section{2. "Nossa cesta básica está na roça": a distribuição de gêneros alimentícios}

Logo no início da crise sanitária que aos poucos se instaurava na consciência pública nacional, foi anunciada pelo Governo brasileiro uma medida abrangente e genérica voltada para todos os povos indígenas no Brasil como uma das principais formas de enfrentamento do Novo Coronavírus nas distintas e diversas regiões que habitam: a entrega massiva de cestas alimentares, chamadas de cestas básicas, às famílias indígenas. Tratou-se de uma parceria entre o Ministério da Mulher, da Família e dos Direitos Humanos (MMFDH), Ministério da Cidadania, Companhia Nacional de Abastecimento (CONAB) e a Funai. No Vale do Javari, são vários os desdobramentos do processo de concretização dessa política pública emergencial que merecem aqui ser analisados.

Instâncias superiores demandaram à Funai as referidas entregas das cestas básicas pelas suas Unidades Regionais. A Funai por sua vez demandou de sua Coordenação Regional no Vale do Javari o levantamento do número de famílias a serem atendidas pelas entregas de cestas alimentares e as possibilidades logísticas de efetivação dessas entregas. O recebimento das cestas e suas mencionadas entregas, não foi algo facultativo às unidades. Também há de se

qualidade de ensino provida nas escolas das aldeias, muitos indígenas mesmo do ensino fundamental têm optado em estudar nas escolas da Sede Municipal de Atalaia do Norte/AM, fazendo com que estes estudantes e algumas de suas famílias fixem residência na cidade até a conclusão dos cursos. 
destacar a padronização e ou generalização quanto à composição das "cestas básicas". Não houve possibilidade de adequação dos itens das "cestas básicas" aos hábitos e preferências alimentares de cada povo, situação que foi muito levantada por representantes indígenas dos povos a serem atendidos. Ressalta-se ainda a questão da falta de adequação e ou de acolhimento ao processo de escuta às verdadeiras necessidades contextuais dos povos indígenas frente o isolamento social de cada povo.

Segundo Informação Técnica elaborada por servidores da CR-VJ/Funai, foi prevista a distribuição de 2066 cestas alimentares para 1033 famílias indígenas que, segundo levantamentos desta mesma Coordenação, habitam atualmente a TI Vale do Javari. Com o peso de $22 \mathrm{Kg}$ cada, o total de cestas previstas para entrega nas 63 aldeias distribuídas ao longo de 6 diferentes calhas de rios que se estendem nos 8.544.482,3 hectares de extensão da Terra Indígena totaliza cerca de 45,5 toneladas.

Com as embarcações que dispõe a CR-VJ/Funai para as entregas das cestas alimentares, o tempo de deslocamento fluvial entre quaisquer aldeias do Vale do Javari e a cidade de Atalaia do Norte, onde localiza-se sua Sede conta-se em dias de viagem. Nos casos de aldeamentos localizados nos altos cursos dos rios esse "tempo" e as dificuldades de acesso se multiplicam e, no período de seca, na vazante dos rios, as condições de navegabilidade se tornam ainda mais precárias e simplesmente inviáveis para embarcações de grande e médio porte nos altos cursos. Diante de tal realidade geográfica, a ação então programada de entrega de cestas alimentares no Vale do Javari através de transporte fluvial já representa tarefa de alta complexidade. Essa condição se aprofunda ainda mais se considerados: o reduzido quadro de servidores atualmente em atividade na unidade, fruto do déficit geral de recursos humanos da instituição como um todo que por sua vez se deve também às precárias condições de trabalho junto a essa Coordenação e de qualidade de vida em uma das cidades com piores Índices de Desenvolvimento Humano (IDH) do Brasil, o que provoca a contínua evasão de seu quadro de servidores. Por fim, em se tratando de uma doença com alta taxa de contágio, os protocolos de ingresso na Terra Indígena devem ser rigidamente obedecidos, com o cumprimento de quarentenas de quatorze dias a ser realizada no interior da T.I, o que prolonga consideravelmente o tempo de execução das atividades de entrega e as complexifica ainda mais.

Depois de seguidos adiamentos da data de chegada das cestas alimentares à sede da CR-VJ/Funai, estas foram desembarcadas no porto da cidade de Atalaia do Norte apenas em meados do mês de julho (15), período em que a vazante dos rios da região já se encontrava em estágio avançado. Apesar de todos os arranjos logísticos feitos pela equipe da CR-VJ/Funai 
para a entrega destes produtos às comunidades do Vale do Javari, articulando-se integrações logísticas com atividades do movimento indígena, do DSEI-VJ e da Marinha do Brasil, até a conclusão deste artigo, as entregas de todas as cestas alimentares nas aldeias dos altos cursos dos rios que drenam a TI Vale do Javari ainda não haviam realizadas. Está em curso, no entanto, desde o início do enfrentamento à COVID-19 na região, tratativas com o Exército Brasileiro para que as entregas nessas aldeias sejam feitas por via aérea em helicóptero próprio da instituição militar, mas não existem ainda previsões para a realização destas ações.

Contudo, como consta na "Informação Técnica no 3/2020/CTL - Atalaia do Norte III VJ/CR-VJ-FUNAI", desde as primeiras comunicações realizadas por rádio e telefone com as aldeias após o início do processo de isolamento das comunidades, lideranças indígenas vêm anunciando que suas principais necessidades, de modo a garantir-lhes segurança alimentar e, assim, a manutenção do isolamento das aldeias, destoam da estratégia de entrega de cestas alimentares.

Os Tüküná-Kanamari, assim como todos os outros povos do Vale do Javari, têm sua base alimentar fundamentada em seus próprios territórios através de suas tradicionais práticas de agricultura, caça, pesca e coleta. Diante de boatos locais de que os indígenas do Vale do Javari estariam supostamente passando fome durante a Pandemia, algumas lideranças contradiziam essa informação afirmando que, apesar das dificuldades enfrentadas neste contexto, nenhum indígena estava passando fome. É ilustrativo o relato orgulhoso de um professor Tüküná-Kanamari da aldeia Bananeira do rio Itacoaí, colhido em comunicação feita por telefone, ao dizer que a sua comunidade não se deviam enviar cestas alimentares, pois, em suas palavras "Nossa cesta básica está na roça. Aqui tem muita macaxeira, abacaxi, cana, mamão, cajú, batata...". Este relato se soma a tantos outros colhidos em comunicações feitas pelos indígenas a estes autores, dizendo que não havia escassez de alimentos, mas que, sim, necessitavam de certos produtos como sal, sabão, isqueiro, anzol, linha e rede de pesca, munição para caça, ferramentas agrícolas entre outros que só estão acessíveis nos núcleos urbanos próximos.

Foi com base nestes e em outros relatos similares que a equipe da CR-VJ/Funai elaborou um plano de trabalho específico para a aquisição de equipamentos de pesca, ferramentas e outros materiais de consumo que, enquanto as cestas alimentares previstas não chegaram, foram distribuídos em todas as aldeias do Vale do Javari. Foi realizada ainda sensibilização da empresa Tramontina para doação de ferramentas a qual fez uma doação com a destinação aos indígenas do Vale do Javari. Mas estas ações contaram com outra barreira para 
sua adequada efetivação. Para um atendimento satisfatório em termos de volume de materiais a serem disponibilizados para cada uma das aldeias, tal como previsto no referido Plano de Trabalho, uma quantidade inédita de produtos para os fornecedores locais deveria ser providenciada em um curto período de tempo. O despreparo destes fornecedores para tal demanda de forma abrupta somada as limitações impostas à circulação de bens no princípio da Pandemia da COVID-19 na região, tornou as ações de entrega de materiais pouco efetivas e desagradou praticamente todas as comunidades que as receberam. Tais descontentamentos, em alguns casos, desembocaram em conflitos internos nas comunidades, gerando inclusive expectativas negativas quanto à quebra do isolamento destas comunidades com o trânsito para a cidade de famílias não atendidas a contento.

\subsection{A disseminação da COVID-19 nas aldeias Tüküná: fato ou fake?}

Ao longo dos últimos meses novos focos de contaminação em comunidades de distintas regiões de rios no interior da TIVJ. Comunidades Tüküná-Kanamari e MatsésMayoruna do médio rio Javari, Marubo do médio e alto rio Ituí e Tüküná-Kanamari do médio e alto Itacoaí já foram alcançadas pela atual Pandemia, tendo casos da COVID-19 registrados entre indígenas nas próprias aldeias 17. O atual quadro da contaminação das aldeias do Vale do Javari, no entanto é estável, segundo informações prestadas pelo DSEI-VJ/Sesai e conforme dados publicados pela Sesai/MS, e, até o fechamento desta publicação, foram registrados apenas 3 óbitos de indígenas com casos da doença confirmados no interior da TI. Contudo, existem sérias denúncias, feitas por setores do Movimento Indígena, quanto à falta de transparência quanto à divulgação das informações acerca da atual crise sanitária no Vale do Javari.

O caso do registro da proliferação da doença entre comunidades Tüküná-Kanamari do rio Itacoaí é ilustrativo do precário fluxo de informações sobre a Pandemia na TI Vale do Javari. Após alertas feitos no início do mês de julho por algumas lideranças sobre a existência de casos suspeitos da doença nas comunidades Hobanã e Terra Nova uma busca ativa foi realizada nessas comunidades pela equipe do Polo Base Remansinho do DSEI-VJ/Sesai em meados daquele mês não tendo sido registrados oficialmente quaisquer casos da doença, apesar

\footnotetext{
${ }^{17}$ É necessário destacar que outros povos em outras calhas de rios, como Mayoruna do Jaquirana e Matis do Rio Branco, registram entre alguns de seus representantes casos confirmados de COVID-19 que, no entanto, foram contraídos, confirmados e tratados fora dessas comunidades.
} 
de terem sido confirmados em comunicação informal alguns casos suspeitos de pessoas sintomáticas. Pouco depois, um caso positivo da doença fora registrado em outra aldeia, a Massapê, confirmado por teste rápido em pessoa vinda da aldeia Hobanã. Com isso, o DSEI$\mathrm{VJ} /$ Sesai acionou sua equipe de resposta rápida que, no final do mês de julho realizou novas buscas ativas em todas as aldeias do rio Itacoaí. Quarenta e dois casos da doença foram então confirmados através de testes rápidos em seis dos oito aldeamentos atualmente povoados naquele rio. No entanto, o DSEI-VJ/Sesai, afirmou que a maior parte dos casos confirmados já se encontrava em estágio de "cura clínica", pois estavam assintomáticos e na avaliação das equipes de saúde, os indígenas teriam contraído a doença a mais de um mês atrás.

Felizmente, foram poucos os casos de agravo da doença entre os Tüküná-Kanamari do Vale do Javari. Apenas uma idosa da aldeia Terra Nova, removida de área pelo DSEIVJ/Sesai por apresentar uma série de problemas de saúde como desnutrição e desidratação graves, teve teste para COVID-19 confirmado e veio a óbito.

\section{4. "E o meu dinheiro 'Funai'?”: ben efícios sociais e POSSIBILIDADES DE quebra de isolamento.}

No momento atual, após cerca de cinco meses desde que os indígenas do Vale do Javari retornaram a suas aldeias e têm mantido o isolamento social das comunidades, pairam as expectativas do trânsito das famílias indígenas em direção à Sede Municipal de Atalaia do Norte com vistas à percepção de seus benefícios sociais e previdenciários para a aquisição de produtos industriais de que necessitam. Apesar das prorrogações dos prazos para atualizações cadastrais, provas de vida e saques destes benefícios, medida que obteve sucesso, no caso do Vale do Javari, na manutenção do isolamento social das comunidades, as expectativas indígenas de possíveis bloqueios e cancelamentos de benefícios têm aumentado, além das necessidades dessas famílias não atendidas pelas entregas de alimentos e insumos às aldeias.

Como se sabe, a crise sanitária provocada pela Pandemia da COVID-19 no Brasil ainda não fora controlada e os riscos de contaminação desses indígenas são reais. Além disso, o represamento, até então, de todas as demandas familiares dos povos do Vale do Javari pelos produtos acessíveis somente nas áreas urbanas próximas, gera o risco de muitas famílias afluírem ao mesmo tempo à cidade de Atalaia do Norte/AM, a qual não conta com estruturas mínimas de acolhimento desses indígenas - falta de saneamento no porto onde os indígenas ficam durante suas estadias na cidade, falta de recursos humanos para assistência social e 
médica, insuficiência do aporte de dinheiro para os bancos locais e mercadorias para os fornecedores. Com isso, existe um grande risco de aglomeração destes indígenas na cidade, o que aumenta as possibilidades de contaminação destes indígenas por COVID-19 e outras doenças que, em eventos passados, afligiram esses povos, especialmente os Tüküná-Kanamari, em situações de aglomeração na cidade.

\section{CONSIDERAÇÕES FINAIS}

Ao serem confrontados os episódios aqui narrados com as reflexões produzidas por Brasileiro (2020) em sua pesquisa, nota-se que as inaptidões históricas das políticas públicas para lidarem com as realidades produzidas pela organização socioespacial dos TükünáKanamari do Vale do Javari foram acentuadas no atual contexto da Pandemia da COVID-19, conformado sérios agravos quanto aos riscos de contaminação destes indígenas.

Apesar de reconhecidos constitucionalmente os direitos à diferença e à especificidade das organizações socioculturais indígenas, o que deveria se refletir na adequação das políticas públicas que visam o atendimento dos distintos povos em seus diversos contextos geográficos, o que se constata pela análise dos fatos aqui descritos é que tais direitos não têm materialidade nos lugares onde as políticas públicas deveriam se efetivar, neste caso, no Vale do Javari. Desta forma, além de não atenderem as atuais necessidades dos Tüküná-Kanamari, algumas destas políticas públicas findam por agravar situações de conflito e de risco a que ficam expostos estes indígenas.

Além disso, ao não serem levados em conta os fatores geográficos regionais que atuam no processo de materialização das políticas públicas e, tampouco, as condições estruturais (financeiras, materiais e humanas) dos órgãos estatais que deveriam garantir a efetivação das mesmas, além do fracasso no atendimento aos interesses indígenas, agentes públicos comprometidos com a defesa dos direitos indígenas acabam sendo sobrecarregados, como no caso da distribuição de cerca de 45 toneladas de alimentos às aldeias indígenas em um território de cerca de 8,5 milhões de hectares que não conta com infraestruturas mínimas de transporte. Isso acaba expondo servidores e colaboradores às situações de insegurança física e, também, jurídica dado o descompasso entre as ações programadas e as estruturas disponíveis para sua realização. Por sua vez, isso acaba por gerar impasses incontornáveis entre os agentes públicos e os indígenas que reivindicam atendimento adequado por parte dos mesmos. 
Ainda, as análises demostram que a setorização das políticas públicas e a incapacidade dos agentes das diferentes instituições, públicas ou não, em concatenar suas ações representa outro desafio a ser encarado para a efetivação das políticas públicas de interesse dos Tüküná-Kanamari.

O Estado brasileiro, enquanto campo de forças políticas em disputa, tem tido, historicamente, um papel adverso ao de garantidor de direitos. O que se tem observado é a existência e persistência de setores privilegiados da sociedade brasileira que não têm interesse na garantia da manutenção das vidas indígenas, mas sim na apropriação privada de seus territórios originários e viabilização de seus projetos econômicos particulares. Desta forma, a efetivação das políticas públicas para os povos indígenas no Brasil sempre dependeu de um contínuo esforço de mobilização social por parte destes indígenas, fato que se apresenta de forma sensível no atual momento histórico de crise sanitária, econômica e política, tanto em nível nacional como internacional.

\section{REFERÊNCIAS:}

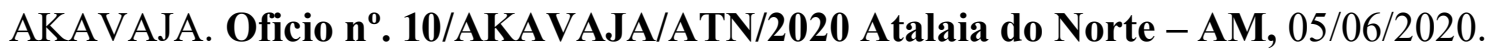

BRASIL. Fundação Nacional do Índio. Coordenação Regional Vale do Javari. Informação Técnica no 3/2020/CTL - Atalaia do Norte III VJ/CR-VJ-FUNAI. 29/05/2020.

BRASIL. Secretaria Especial de Saúde Indígena. Nota à Imprensa, "Quatro profissionais do Distrito Especial Indígena Vale do Javari testam positivo para COVID-19”, 04/06/2020.

BRASILEIRO, Danielle Moreira. Expressões da Questão Indígena e da Proteção Social: O Caso dos Kanamari(Tüküná) na Terra Indígena (T.I) Vale do Javari (2010-2020). Manaus, UFAM, 2020. (Tese de Doutorado).

BRASILEIRO, Danielle Moreira, Corrêa da Silva, Heloísa Helena. Oliveira, Adolfo de Capítulo de Livro: A proteção social e os povos indígenas na Amazônia: políticas públicas e direitas sociais no espaço de tríplice fronteira (Brasil, Colômbia, Peru); no tempo, a FUNAI in, Indígenas en las ciudades de las Américas: Condiciones de vida, procesos de discriminación e identificación y lucha por la ciudadanía étnice.

CARVAlHO, Maria Rosário Gonçalves de. Os Kanamari da Amazônia Ocidental (AM): história e etnografia. São Paulo: USP, 1998. (Tese de Doutorado).

CARVALHO, Maria Rosário Gonçalves de; REESINK, Edwin B. Ecologia e sociedade: uma breve introdução aos Kanamari. In: MAGALHÃES, Antônio Carlos. (Org.). Sociedades indígenas e transformações ambientais. Belém: NUMA/UFPA, 1993. p.113-153. 
CORRÊA DA SILVA, Heloisa Helena. Expressões da Assistência Social no Médio Juruá Amazonas, Editora da Universidade Estadual Federal do Amazonas, Manaus, 2012. ISBN: 978-85-7401- 471-5.

COSTA, Luís. De Povos Indígenas no Brasil. Kanamari, $<$ https://pib.socioambiental.org/pt/Povo:Kanamari>, acesso em 21.08.2018. 2014.

COSTA, Luís Antônio. As Faces do Jaguar. Parentesco, História e Mitologia Entre os Kanamari da Amazônia Ocidental, PPGAS-Museu Nacional Rio de Janeiro, Tese de Doutorado, 2007.

FREITAS, Marcílio. “Amazônia e Complexidade, In Amazônia. Brasil: Chiado, 2017. p. 1936.

FREITAS, Marcílio “Homem-natureza-cultura. Amazônia. Brasil: Chiado, 2017. p.87-106.

LABIAK, Araci Maria. Frutos do Céu e Frutos da Terra: Aspectos da Cosmologia Kanamari no Warapekom. Florianopolis, 1997.

NEVES, Eduardo Góes. Arqueologia da Amazônia. Descobrindo o Brasil. Jorge Zahar Editora, Edição do Kindle, 2006. ISBN: 978-85-378-0431-5

NEVES, João Lino de Oliveira. Volta ao Começo: Demarcação Emancipatória de Terras Indígenas no Brasil, Coimbra, agosto de 2012. 137 anos de sempre: um capítulo da história Kanamari do contato.

Florianópolis: UFSC, 1996. (Dissertação de Mestrado).

REESINK, Edwin B. Imago mundi Kanamari. Rio de Janeiro: UFRJ/Museu Nacional, 1994. (Tese de doutorado).

. Algumas considerações sobre o parentesco entre os Kanamari.

Salvador: UFBA, 1989. (Manuscrito).

TOCANTINS, Leandro. O Rio comanda a vida: uma interpretação da Amazônia. Rio de Janeiro, Ed. A noite, 1973.

.Amazônia: natureza, homem e tempo. Rio de Janeiro. Ed.

Conquista, 1982. 